\title{
EMPLOYING READING RACETRACK AND FLASHCARDS TO ENHANCE SIGHT WORDS RECOGNITION AMONG STUDENTS WITH LEARNING DISABILITY
}

\author{
Norhayati Othman ${ }^{\mathrm{a}}$, Mohd Mokhtar Tahar \\ ${ }^{\mathrm{ab}}$ National University of Malaysia, Malaysia \\ E-mail : yati.othman87@gmail.com
}

\begin{abstract}
Effective sight words instruction will improve a student's overall reading abilities. This study involved a replication of an instructional reading strategy in measuring the effects of pairing reading racetracks with flashcards in enhancing sight words recognition of student with learning disability. Two six-year old students have been selected by their classroom teacher to participate based on their reading performance. Data were collected based on the number of corrects and errors of selected sight words presented to them. The results indicated that each student improved their performance on sight words reading when racetrack and flashcards were used. The efficacy of employing reading racetracks and flashcards at the classroom level was discussed.
\end{abstract}

Keywords: reading racetracks, flashcards, sight words, learning disability;

Reading is the process of constructing meaning from written texts. It is a complex skill requiring the coordination of a number of interrelated sources of information (Anderson et al., 1985). Reading is one fundamental skill in learning that a particular student should be equipped with in order to succeed in academic studies and future life. When the technological revolution is continuously making progress in this era, reading remains as one compulsory basic skills one needs in order to be successful in life. Students who struggled in early reading likely continue to experience failures in later academic studies and later in life.

In the early stages of reading, children have to acquire and practice decoding and word recognition skills in order to develop fluent automatic word reading, whereas the ability to understand and appreciate written texts continue to develop throughout life. Nevertheless, students with difficulties in reading will gradually lose interest in reading as they unable to fully understand a written text. Those who secure early literacy skills have the strength to continuously develop in their knowledge and skills while those who fail to develop early skills fall further and further behind. In the "Matthew Effect," a "the rich get richer while the poor get poorer" phenomenon.

Some elements of excitement should be incorporated into reading instructions to avoid frustrations among students with learning disabilities (Koran \& McLaughlin in Charlton, Williams \& McLaughlin, 2005). Game is one activity that bring excitement to students at all levels. It may reduce the complexity of drill (Koran \& McLaughlin, 1990 in Charlton, Williams, \& McLaughlin, 2005) and incorporated an element of fun that helps to motivate students with learning disability. On top of that, Harris in Schifter (2013) proposed that stressful drill and practice can be replaced with game-like activities.

Reading racetrack have been demonstrated to be effective and effortless to be implemented for students with difficulties in reading (Rinaldi, Sells, \& McLaughlin, 1997). Reading racetrack can be used in reading instruction that could improve students' reading fluency. The words filled up in the reading racetrack have to be carefully selected to avoid having any two words on a particular racetrack that were either auditorily or visually similar. The words used in a reading racetrack could be selected from a variety of materials such as Dolch Sight Words, Fry Word Lists, words from passages of reading texts, trade books, word lists, vocabulary lists, etc. (Romjue, McLaughlin \& Derby, 2011). Reading racetracks have been demonstrated to be effective (Rinaldi \& McLaughlin, in Kaufman, Leah; McLaughlin, T F; Derby, K Mark; Waco, Theresa, 2011) and it can be paired with flashcards to improve sight word recognition (Falk, Band, \& McLaughlin, 2003).

This study was carried out to measure the performance of two six-year-old male and female students who had difficulties in reading according to testing and teacher's observation in classroom. The initial research question posed for the study was as follow: Will a reading racetrack paired with flashcards improve students' sight words reading? Another purpose was to replicate and extend the use of 
reading racetracks and flashcards to other population of students.

\section{METHOD}

Two preschool students were selected by their classroom teacher upon difficulties in reading that was confirmed after several assessment conducted in the classroom. The participants were one boy and one girl of 6 year-old.

Haikal, was a pleasant and cooperative boy. He is a highly motivated student but experienced difficulties in reading. He added, omitted, and substituted words and letters within words. He made repeated reversals in recognising the letters, $b, d, p$, and $q$.

Aneesa, was a shy girl and always withdrawn from group activity. She had a positive attitude toward school but had low motivation. Her blending and auditory discrimination were good, but visual memory and word recognition were weak.

The students received one hour of remedial reading instruction in addition to the normal classroom time each day.

Reading Racetrack is an intervention that puts a sight word list into a game-like 'Racetrack' format. (Rinaldi, Sells, \& McLaughlin in Kaufman, McLaughlin, Derby, Mark, Waco, \& Theresa, 2011). The students read aloud from a 'racetrack' wordlist for 1 minute and the reading performance was recorded, then they repeat the reading of the words in the racetrack several times as they attempt to reach a pre-set fluency goal.

These materials were used during the employment of reading racetrack: (1) Master list of sight words (Dolch Word List); (2) Reading Racetrack form filled out with words from the master sight-word list; (3) Reading Racetrack Score Sheet; (4) Stopwatch.

The Dolch Sight Words list is the most commonly used set of sight words. Educator Dr. Edward William Dolch developed the list in the 1930s-40s by studying the most frequently occurring words in children's books of that era. The list contains 220 "service words" plus 95 high-frequency nouns. These words comprise $80 \%$ of the words that could be found in a typical children's book. Once a child knows this list of words, it makes reading much easier, because the child can then focus his or her attention on the remaining words.

\section{Conditions}

Pre-Assessment. A pre-assessment of sight words was administered for the three students using Dolch Sight Word List that contain graded word list. The list were chosen to identify known and unknown sight words of each student. The students were asked to identify selected sight words from Dolch Sight Words list that were presented on $3 \times 5$ index cards. The sight words that were successfully decoded by the students were recorded.

The sets and corresponding racetracks were developed after the completion of the pre-assessment with the students. The word list were constructed in a way that words that were visibly or auditory similar were not introduced at the same time. Each list contained seven known words and seven unknown words. The words were written with a black marker on a $3 \times 5$ index card for instruction. The racetracks were then constructed with four-time appearance of each words.

Baseline (B). The flashcards were presented to the students individually and they were asked to verbally respond within 5 seconds. The participants were asked to say "I don't know" or "pass" if they do know any words presented to them. There was no feedback given regarding the accuracy of participants' responses. Notes and remarks were made on a checklist that contained all words presented to the participants. An "X" was placed to the word that resulted in an error and a corresponded mark was written next to a correct response. The marks were counted and totalled up for each participant after data collection was completed.

Flashcards and reading racetrack $(R R)$. Data were taken after baseline and instruction on words began using both flashcards and reading racetracks. The flashcards were presented to the participants individually. The participants were asked to say the words aloud. The researcher provided an instruction when they encounter an unknown word during this stage. The correct way of pronouncing the words will be modelled to the participants. Then, the participant was asked, "What word is this?" The participant would say the word.

The flashcards were presented three times to the participants before the reading racetracks were introduced. A practice session was completed to allow the participant to go around the entire racetrack saying each word. Immediate error correction was provided using the same model, lead, and test format used during flashcards instruction if the participants missed any of the cells in the racetrack. Once the practice round was completed, the official one-minute timing and recording was taken. "All right get ready, on your mark, get set, go" was prompted to each participant and they read or provide an answer for each cell pointed. As the participants were going around the track, a corresponded mark will be recorded on a printed sounds and words checklist to keep track of corrects and errors. At the end of one-minute timing, an " $\mathrm{X}$ " was placed at the cell that they ended on in order to get the participants to be able to keep track of their own progress and see how far they have had gotten. No feedback or praise was given during the timings, except for saying "good job" at the 
end of the timed-session. The total number of corrects and errors were counted and recorded after the session was completed.

Reversal $(R V)$. Once the participants were showing a measured progress within their sets, a reversal session was carried out. This session was conducted by presenting the words on the flashcards. The aim of this session was to determine if the participant could recall the item without the use of the reading racetrack.

Follow-up Probes. Once four word lists were completed, follow-up probes were carried out. During follow-up sessions, the participants were asked to read all 28 words that had been the unknown words within the four previous racetracks. There were a total of four follow-up sessions for each participant, regardless of how many corrects or errors each session. This phase lasted of four sessions.

\section{FINDINGS AND DISCUSSION}

\section{Findings}

Participant 1. The number of words read correctly and errors made during baseline and reading racetrack intervention are shown on Figure 1.

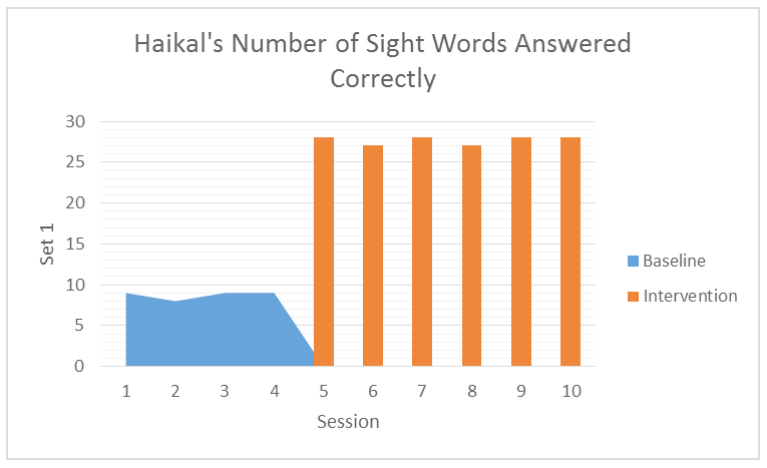

The number of correct and error words during baseline and reading racetrack intervention are presented on Figure 1. During baseline for List 1, this participant read 9 words correctly and made 5 errors. Throughout the reading racetrack intervention, he made an average of 27.6 corrects with 0.4 errors. He finished List 1 by reading all 14 words correctly with no errors.

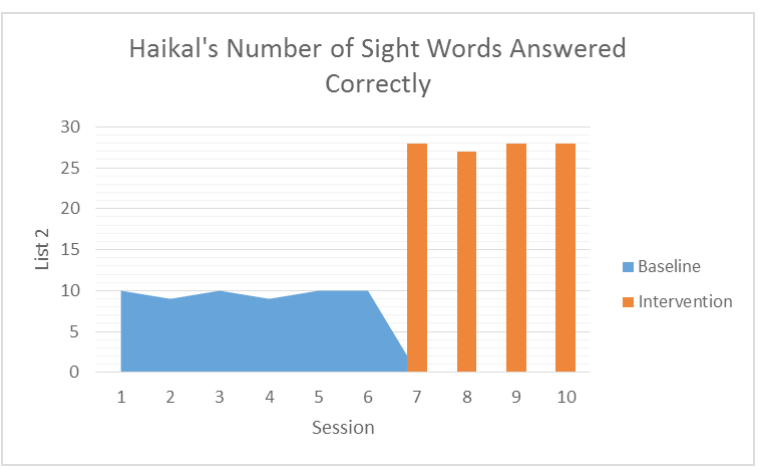

He had 10 corrects and 4 errors during baseline for List 2. Throughout the reading racetrack intervention, he made an average of 27.75 corrects with 0.25 errors. He completed this word list with 14 words correct and 0 errors. For List 3, he had 8 corrects and 6 errors for baseline. During the reading racetrack intervention, he made an average of 27 correct with only 1 error (range from 26 to 28 corrects and 0 to 2 errors.) He was able to read all 14 words correctly from the list during reversal.

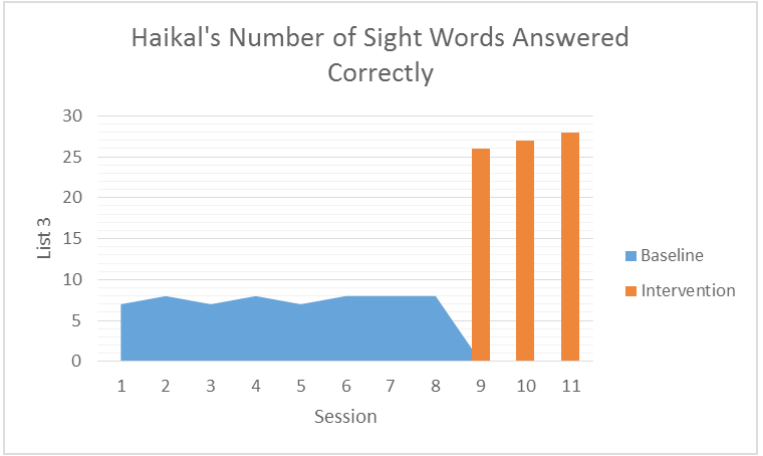

On List 4, participant 1 had 6 corrects and 8 errors for baseline. During the intervention, he made an average of 24 corrects and 4 errors (range from 26 to 22 corrects and 2 to 6 errors). He was able to read 13 of the 14 words from the list during reversal. On the review racetrack, the participant made an averaged 27 corrects and 1 error (range from 28 to 26 and 2 to 0 errors).

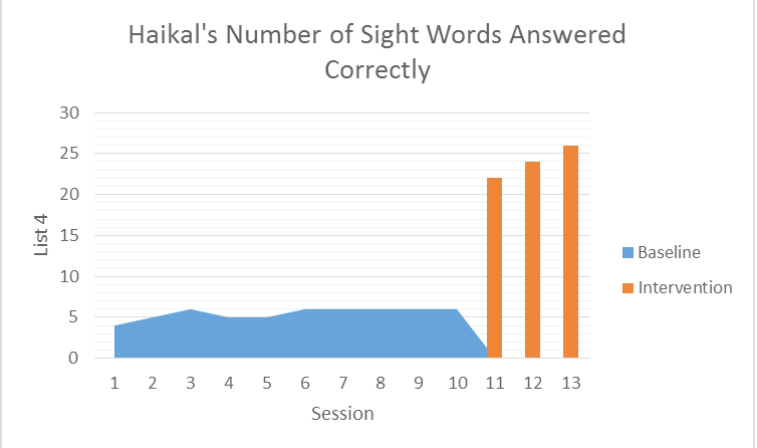

Participant 2. The number of words read correctly and errors made during baseline, the reading racetrack intervention and reversals are shown on Figure 2. During baseline for List 1, the participant read 8 words correctly and made 6 errors. Throughout the reading racetrack intervention, she made an average of 27 corrects with 1 errors. She read all 14 words correctly during reversal and make 0 errors.

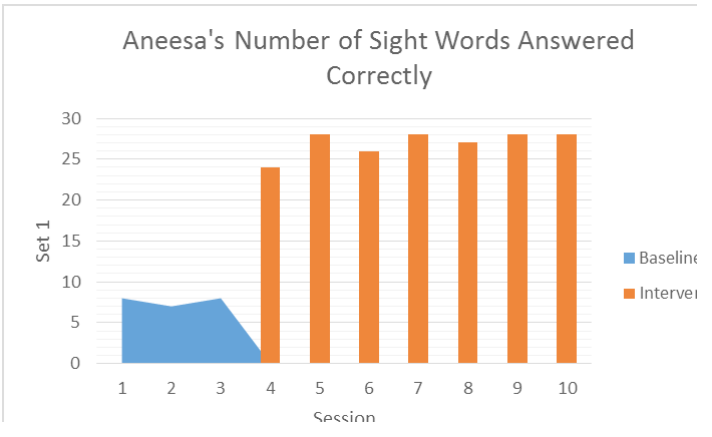


For List 2, this participant had 6 corrects and 8 errors during baseline. During the reading racetrack intervention, she made an average of 26.4 corrects and 1.6 errors (range from 25 to 27 corrects and 1 to 3 errors.) She read all 14 words correctly with no errors during reversal.

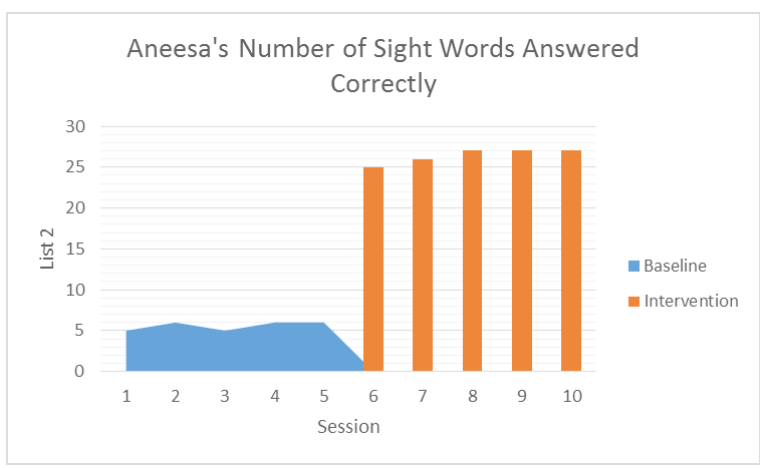

On List 3 , this participant had 10 corrects and 4 errors during baseline. Throughout the reading racetrack intervention, she made an average of 27.7 corrects and 0.3 errors. The participant read all 14 words correctly with no errors during reversal.

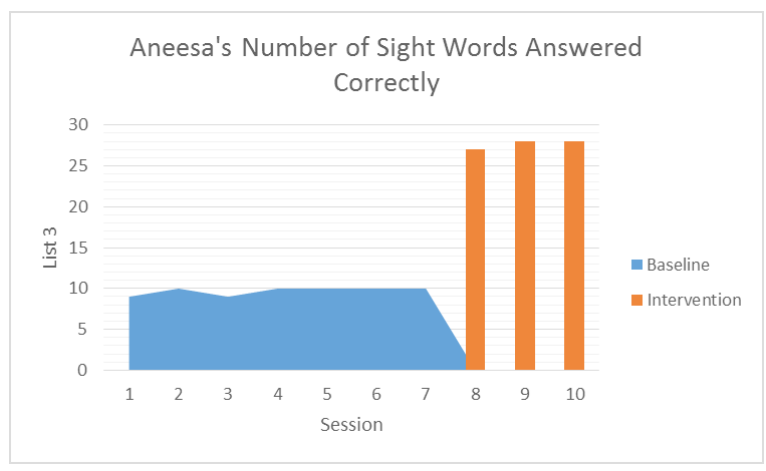

On List 4, this participant had 8 corrects and 6 errors during baseline. During the intervention, she made an average of 28 corrects and 0 errors. She then was able to read all 14 words correctly with no errors during reversal. Finally, during the review reading racetrack phase, the participant made an average of 27.8 corrects and 0.2 errors.

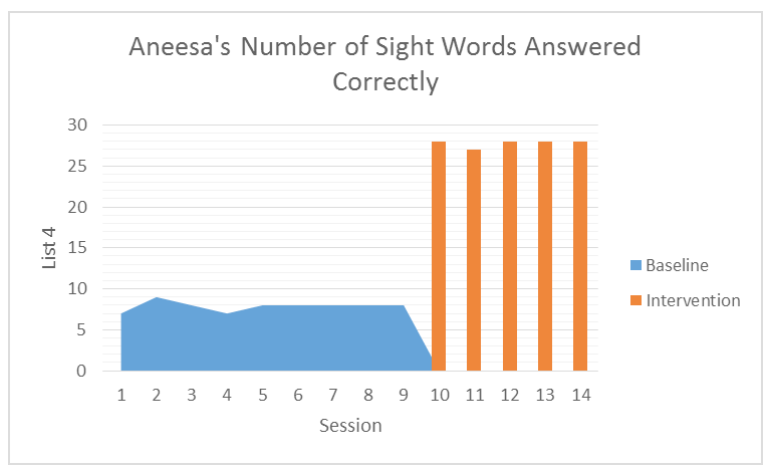

\section{Discussion}

This result has proven that the procedure of pairing reading racetrack with flashcards was effective to both participants. The improvement in sight words recognition and the reduced error made was a direct result of the reading racetrack procedure.

The first participant looked very anxious when new words were presented to him. He was taking a longer time to finish the first session when new words were introduced. He seem frustrated when reading racetrack 4 was presented to him. During baseline, he was only able to read 6 words correctly out of 8 his known words. During the racetrack intervention, he would simply passed on the words he did not know. However, he kept on providing response during procedure.

The second participant was very interested in the reading racetrack procedures and she kept on being motivated until the final racetrack and the review session. She enjoyed working with the teacher in oneone-one approach throughout the procedure. She would inform the researcher whenever she wanted to play with the racetracks. This demonstrated that the gamelike procedure has brought excitement to her.

Another aspect that made this procedures effective is reading racetracks were also practical in terms of time, money and effort. To prepare for the session, the researcher took about two minutes to create a new racetrack if needed, and then made two copies, and the actual session was carried out in less than five minutes. There was no cost to the researcher unless copies had to be made outside of the school. The procedure was easy to implement in the classroom and could easily be implemented at home or other setting. The enhancement of student sight-word vocabulary has been linked to improving long-term outcomes for students with and without disabilities (Farkas \& Beron, 2004).

There were some limitations when the research were conducted. In addressing the assessment problem, the researcher could employ some type of criteria, such as corrects and errors per minute to establish the instructional level for the participants. There were only two participants included as that was the number of students recommended by the classroom teacher. Adding mote participant to this study would bring an additional validity to the outcomes (Horner, Carr, Halle, McGee, Odom, \& Wolery, 2005). Another limitation was that not enough data were collected during experimental condition. Only one data point was plotted for each baseline condition. With only one data point, determining trend, level of performance, and stability was not possible. Similarly, only one measure of performance was taken during reversal condition.

This study gained similar outcomes with the previous research (Rinaldi et al., 1997) and it shows that reading racetracks could be effective with a student 
with mild intellectual disabilities. Racetrack procedures could be employed with other subject matter areas such as math (Beveridge, Weber, Derby, \& McLaughlin, 2005).

When students are provided with sight word instruction, their overall reading abilities as well as their self-confidence improve. According to Musti-Rao et al., in Hayes, 2016, "instruction in sight words not only can result in a corresponding increase in reading fluency and comprehension but also can improve students' confidence levels and reduce their frustration with reading" (p. 34). The findings from this research study as well as that of Musti-Rao in Hayes, 2016, provide an implication that teachers may incorporate sight word instruction into their classroom schedule.

Besides, teachers may create a literacy-rich classroom environment for the students to have multiple opportunities that engage with sight word reading. During data analysis, the researcher had found that students need to be engaged in other forms of literacy, in addition to sight word instruction, in order to become adequate readers. According to Axelrod, et al., in Hayes, 2016, "high-quality literacy programs require a literacy-rich environment with many materials to support children's learning" (p. 17). In order for students to stay engaged in learning, teachers need to create an inviting classroom environment through the use of different kinds of print around the room. Axelrod et al., in Hayes, 2016, provides examples of the different kinds of print that should be seen such as books, magazines, writing materials, lists, charts,

\section{REFERENCES}

Anderson, R.C., Hiebert, E.H., Scott, J.A. \& Wilkinson, I.A.G. (1985) Becoming a Nation of Readers: The Report of the Commission on Reading. Education Resources Information Centre.

Beveridge, B.R., Weber, K.P., Derby, K.M. \& McLaughlin, T.F. (2005). The Effects of a Math Racetrack with Two Elementary Students with Learning Disabilities. The International Journal of Special Education, Vol 20, No.2.

Charlton, B., Williams, R.L. \& Mclaughlin, T.F. (2005) Educational Games: A Technique to Accelerate the Acquisition of Reading Skills of Children with Learning Disabilities

Falk, M., Band, M. \& McLaughlin, T.F. (2003) The Effects of Reading Racetracks and Flashcards on Sight Word Vocabulary of Three Third Grade Students with a Specific Learning Disability: A Further Replication and Analysis. International Journal of Special Education, Vol 18, No.2. labels, signs, and writing samples from children and adults" (p. 17). All of these kinds of prints are readily available to teachers, and therefore should be displayed around the room in order to provide support to students.

\section{CONCLUSION AND SUGGESTION}

There are two significant conclusion that were deduced out of the data analysis. This study proved that reading racetrack procedure that was paired with flashcards had increased students' number of sight words recognition, and reading racetrack procedures improved students' confidence in sight words reading. This information indicates that effective sight word instruction did, in fact, increase students' overall reading abilities.

This study demonstrates that reading racetracks paired with flashcards was an effective way to teach sight words to two participants with mild disabilities on one-on-one approach. To better evaluate the effects of reading racetracks, data could be gathered from various settings and with students with various disabilities. When students are provided with sight word instruction, their overall reading abilities as well as their self-confidence improve. Teachers may incorporate sight word instruction into their classroom schedule. Besides, teachers may create a literacy-rich classroom environment for the students to have multiple opportunities that engage with sight word reading.

Farkas, G. \& Beron, K. (2004) The Detailed Age Trajectory of Oral Vocabulary Knowledge: Differences by Class and Race. Social Science Research, 33, 464-497.

Hayes, C. (2016) The Effects of Sight Word Instruction on Students' Reading Abilities. Fisher Digital Publications. Education Masters. Paper 327.

Horner, R.H., Carr, E.G., Halle, J., McGee, G., Odom, S. \& Wolery, M. (2005) The Use of Single-Subject Research to Identify Evidence-Based Practice in Special Education. Exceptional Children,Vol. 71. Na. 2. pp. 165-179.

Kaufman, L., McLaughlin, T.F., Derby, K.M. \& Waco, T. (2011) Employing Reading Racetrack and DI Flashcards With and Without Cover, Copy, and Compare and Rewards to Teach Sight Words to Three Students with Learning Disability in Reading. Educational Research Quarterly, 34.4: 24-44. 
Rinaldi, L., Sells, D., \& McLaughlin, T. F. (1997). The effect of reading racetracks on the sight word acquisition and fluency of elementary students. Journal of Behavioral Education, 7, 219-233.

Schifter, C. C. (2013). Games in learning, design, and motivation. In M. Murphy, S. Redding, \& J. Twyman (Eds.), Handbook on innovations in learning (pp. 149-164). 